14. Левенок В.П. Отчёт о полевых работах Верхне-Донской археологической экспедиции Ленинградского отделения ИА РАН СССР и ЛОКМ в 1964 году // Архив ИА РАН. Ф. 1. Р-1.

15. Левенок В.П. Неолитические поселения на p. Матыре под Липецком // Краткие сообщения Института археологии. Вып. 111. М.: Наука, 1967. C. $116-120$.

16. Левенок В.П. Долговская стоянка и её значение для периодизации неолита на Верхнем Дону // Материалы и исследования по археологии СССР. Т. 131. М.: Наука, 1965. С. 223-231.

17. Левенок В.П. К характеристике культур мезолита, неолита и бронзы в Воронежском Подонье // Известия Воронежского государственного педагогического института. Т. 45. Воронеж: Издательство ВГПИ, 1964. С. 142-150.
18. Левенок В.П. Неолит Верхнего Дона и его место среди неолитических культур лесостепной зоны Европейской части СССР: автореф. дис. ... канд. ист. наук. Л., 1969. 19 с.

19. Левенок В.П. Неолитические племена лесостепной зоны Европейской части СССР // Материалы и исследования по археологии СССР. № 172. М.: Наука, 1973. С. 185-197.

20. Левенок В.П. Памятники днепро-донецкой культуры в лесостепной полосе РСФСР // Краткие сообщения Института археологии. Вып. 126. М.: Наука, 1971. С. 108-114.

Статья написана при поддержке гранта РФФИ 18-49-480004 «Поселение Доброе 9 в системе ранненеолитических древностей лесостепного Подонья).

\title{
EARLY NEOLITHIC STONE INDUSTRY OF THE UPPER DON
}

(C) 2018

Smolyaninov Roman Viktorovich, candidate of historical sciences, head of Archeology and Ethnology Office Yurkina Elizaveta Sergeevna, senior laboratory assistant of Russian and World History Department Lipetsk State Pedagogical P. Semenov-Tyan-Shansky University (Lipetsk, Russian Federation)

Abstract. Features of the flood plain settlements of the river Don watershed and its tributaries is the fact that almost all of them are multi-layered. Until recently it was not possible to talk about the Early Neolithic stone industry of the Upper Don. All conclusions about Early Neolithic material culture in this territory were done by A.T. Sinyuk, based on the Middle-Don site. He described tool industry as blade technique. The paper mentions the most important sites and gives a review of Early Neolithic stone industry of the Upper Don. Nowadays there are materials of the 4 Early Neolithic cultures on the Upper Don territory: Middle-Don (72 sites), Karamyshevo (26 sites), Upper-Volga (4 sites) and Elshanskaya (4 sites) cultures. The earliest materials in the research area date VI mill. cal BC. The data on the stone industries of the Elshanskaya and Upper-Volga cultures in the Upper Don are absent. There are stone collections, which could be connected only with the Middle-Don and Karamyshevo Early Neolithic cultures. This industry could be described as flake technique.

Keywords: Early Neolithic; flint; quartzite; Middle-Don Neolithic culture; Karamyshevo Neolithic culture; Upper Don; radiocarbon dating; tool; flake; forest-steppe; excavation area; site; arrowhead; scraper; knife; polyfunctional tools; blade; core; typological analysis.

УДК 902903023

Статья поступила в редакцию 14.06.2018

\section{НОВЫЕ ДАННЫЕ О РАННЕМ НЕОЛИТЕ СТЕПНОГО ПОВОЛЖЬЯ}

(C) 2018

Юдин Александр Иванович, доктор исторических наук, заместитель директора по научной работе Научно-исследовательский центр по сохранению культурного наследия (2. Саратов, Российская Федераиия)

Выборнов Александр Алексеевич, доктор исторических наук, профессор, заведующий кафедрой отечественной истории и археологии

Самарский государственный сочиально-педагогический университет (2. Самара, Российская Федераиия)

Аннотация. Вопрос выделения раннего неолита на различных территориях является одним из наиболее сложных для исследования. Ранний неолит степного Поволжья долгое время был неизвестен. Это объясняется малочисленностью памятников эпохи неолита в интересуемом регионе. Ситуация изменилась после исследования Варфоломеевской стоянки. Нижний слой этого опорного памятника орловской культуры относился к среднему неолиту, слои 2Б и 2А - к позднему неолиту. Данная версия основывалась на ограниченной источниковой базе и малочисленных радиоуглеродных датах, часть из которых носили дискуссионный характер. Новые полевые исследования 2014-2017 годов на трех раскопах поселения Орошаемое и значительная серия радиоуглеродных дат по различным органическим материалам, полученным в различных лабораториях (включая AMS), позволили пересмотреть периодизацию как Варфоломеевской стоянки, так и орловской культуры в целом. Это позволяет сделать типологический анализ материалов, а также техникотехнологический анализ керамического инвентаря. Так, наиболее ранняя керамика изготовлена из ила с естественной примесью раковин моллюсков. Нижний слой памятника теперь определен как ранненеолитический, слой 2Б - средний неолит, слой $2 \mathrm{~A}$ - поздний неолит.

Ключевые слова: степное Поволжье; Северный Прикаспий; стоянка; ранний неолит; средний неолит; поздний неолит; орловская культура; керамика; каменный инвентарь; стратиграфия; периодизация; хронология; радиоуглеродное датирование; технико-технологический анализ. 
Проблема раннего неолита Нижнего Поволжья, а также Северного и Северо-Западного Прикаспия всегда оставалась актуальной ввиду малого количества материалов на немногочисленных памятниках этих регионов. Полевые исследования последних лет и серия новых радиоуглеродных дат изменили ситуацию к лучшему и дали возможность более детально охарактеризовать комплексы раннего неолита.

При публикации материалов Варфоломеевской стоянки отмечалось, что ранние орловские памятники пока неизвестны $[1$, с. 145]. К среднему неолиту были отнесены нижний слой Варфоломеевской и часть материалов Кушумской стоянки. Сказалось как наличие всего одной даты, достаточно ранней, но с очень большим доверительным интервалом, так и типологическое сопоставление с памятниками раннего неолита сопредельных регионов - Северным и Северо-Западным Прикаспием. Стоянки раннего неолита в Прикаспии (Кугат IV, Кулагайси и ТуБузгу-Худук) включали незначительное количество артефактов $[2$, с. 11,12 , рис. 41$)$ и проводить сравнение с более выразительными и многочисленными находками нижнего слоя Варфоломеевской стоянки казалось некорректным. Вопрос о раннем неолите для степного Поволжья остался открытым [1, с. 145150], так как типологически находки из нижнего слоя Варфоломеевки имели уже вполне сложившийся облик по сравнению с материалами ранненеолитических стоянок Ту-Бузгу-Худук, Кугат IV и Кулагайси.

Поэтому сопоставление и синхронизация находок нижнего слоя Варфоломеевки проводились с материалами двух нижних слоев (3 и 2) стоянки Джангар [3; 4 , с. 66-86] и с памятниками каиршакского типа [5, c. $92-105 ; 6$, с. $18-46 ; 2$, с. $8-11]$. В калиброванном значении время среднего неолита было определено первой половиной - второй четвертью VI тыс. до н.э. Для стоянки Каир-Шак III это $6950 \pm 100$ л.н. (ГИН 5905 ) или 6010-5660 ВС и $6720 \pm 80$ л.н. (ГИН 5927) или 5740-5480 ВС. Единственная на то время дата для нижнего слоя Варфоломеевской стоянки $6980 \pm 200$ л.н. (ГИН 6546) или 6250-5500 ВС - подвергалась исследователями сомнению из-за большого доверительного интервала в 200 лет.

Полученная за последнее десятилетие значительная серия радиоуглеродных дат для памятников Нижнего Поволжья [7; 8] позволила скорректировать наши представления о хронологии неолита - энеолита региона, особенно в части раннего неолита.

Оказалось, что более ранние материалы памятников Кугат IV и Кулагайси в Северном Прикаспии, выделенные в свое время типологически, имеют даты, совпадающие с рядом дат стоянки Каиршак III [8, с. 56, табл. 1: 1, 2 для Кугат IV; с. 60, табл. 1, с. 61 для Кулагайси; с. 56-57, табл. 1: 8-13 для Каиршак III]. Причем ряд дат для Каиршак III оказался даже старше [8, с. 56, табл. 1: 3-5, 7]. Разумеется, этому можно найти различные объяснения, но показателен сам факт синхронности типологически более ранних памятников с Каиршаком III на определенном отрезке раннего неолита. Это закрывает вопрос о раннем неолите Северного Прикаспия, а в распоряжении исследователей для характеристики раннего неолита есть информативный комплекс стоянки Каиршак III, материалы которого на порядок превышают находки на стоянках Кугат IV и Кулагайси, не сохранивших культурный слой. Очевидно, что именно малочисленность выборки материалов на последних послужила одной из причин их отнесения к более раннему времени относительно каиршакских.

Но в таком случае надо уточнить хронологическую позицию в рамках неолита и нижнего (3) слоя Варфоломеевской стоянки. Новые радиоуглеродные определения по керамике для нижнего горизонта Варфоломеевской стоянки предоставляют такую возможность. Ранее уже предполагались достаточно близкие хронологические параметры нижнего слоя Варфоломеевской стоянки с Каиршаком III, а после нескольких лет исследований поселения Орошаемое и получения нескольких дат по различным материалам для нижнего слоя поселения Орошаемое (раскоп Орошаемое и Алгай 1) эти предположения нашли свое дальнейшее подтверждение. Кроме того, была пополнена и коллекция ранненеолитических артефактов, находящих прямые аналогии в нижнем слое Варфоломеевской стоянки [9-11].

Комплексные исследования поселения Орошаемое на р. Большой Узень близ районного центра Александров Гай Саратовской области проводятся с 2014 года. За четыре полевых сезона исследовано

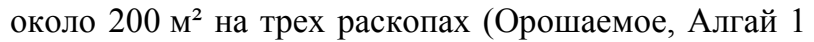
и Алгай 2). Памятник стратифицированный. На двух участках прослежена следующая последовательность культурных напластований снизу вверх: орловские материалы, прикаспийские, хвалынские. Еще на одном раскопе (Алгай 1) доминировали неолитические материалы и единично представлены артефакты прикаспийской культуры. Хорошо расчленяются два неолитических слоя, которые соотносятся со слоями $2 Б$ и $2 \mathrm{~A}$ Варфоломеевской стоянки. Ряд стратиграфических данных показывает, что при дальнейших раскопках будет выделен и третий (пока прослеживается на локальных участках), более ранний горизонт, как это было и на Варфоломеевской стоянке.

Две новые даты происходят из нижнего неолитического слоя раскопа Орошаемое. Они получены по углю из пластов 27 и 28 (раскопки 2016 года): $7010 \pm 110$ BP (6072-5674 cal BC) (SPb-2143) и $7245 \pm 60$ (6227-6015 cal BC) (SPb-2141). Даты совпадают с радиоуглеродными определениями по керамике из нижнего уровня слоя 2Б Варфоломеевской стоянки $-7280 \pm 100(6250-5890 \mathrm{cal} \mathrm{BC})(\mathrm{Ki}-14374)$ и $7230 \pm 90(6230-5980 \mathrm{cal} \mathrm{BC})(\mathrm{Ki}-14368)$ и датой по углю из нижнего (3) слоя $-6980 \pm 200(6250-5500 \mathrm{cal}$ ВС) (ГИН-6546).

Третья дата получена по гуминам с уровня жилища на раскопе Алгай 1: SPb-2144 - 7284 \pm 80 ВР (6271-6008 calBC). Она оказалась очень близка к приведенным выше двум датам по углю из неолитического слоя в раскопе Орошаемое, а также хронологии нижнего (3) слоя Варфоломеевской стоянки.

То есть три полученные даты укладываются в ранний этап неолита. Это подтверждает высказанное предположение о наличии более раннего слоя на поселение Орошаемое в неолитическом горизонте.

Этот культурный слой на раскопах Орошаемого уже можно идентифицировать не только по образцам, взятым из нижнего уровня для датировки, но и выделить как самостоятельный литологический горизонт. Ранний культурный слой на некоторых 
Юдин А.И., Выборнов А.А.

участках прослеживается стратиграфически, что подтверждается и составом содержащихся в нем находок. Они немногочисленны, и только на основании их всесторонне охарактеризовать ранний этап орловской культуры не получится. Но, с другой стороны, имеющаяся керамика и каменные изделия, хотя и не включают все категории предметов с ранненеолитическими признаками, полностью соответствуют находкам в нижнем слое Варфоломеевской стоянки. Здесь, как и в случае с Кугат IV и Кулагайси в Северном Прикаспии, следует учитывать незначительность выборки.

Стратиграфически к раннему культурному слою на раскопе Алгай 1 относится участок в квадрате 8 , первоначально определенный как яма 2 [10, с. 7-8]. Она частично попала в северо-восточный край раскопа. Длина ямы по восточному борту раскопа составляет 2,8 м, по северному - 2,15 м. Стенки ямы полого опускаются ко дну. Перепад от верхнего уровня материка до материкового дна от 0,38 до 0,5 м. Данную «яму» можно трактовать и как котлован жилища (часть его) и как самый нижний культурный слой (рис. 1: 1). Заполнение этого котлована отличается более светлым цветом от вышележащего культурного слоя, что позволяет предполагать его формирование в несколько иных климатических условиях относительно вышележащих слоев и, соответственно, более ранний возраст находок в нем.

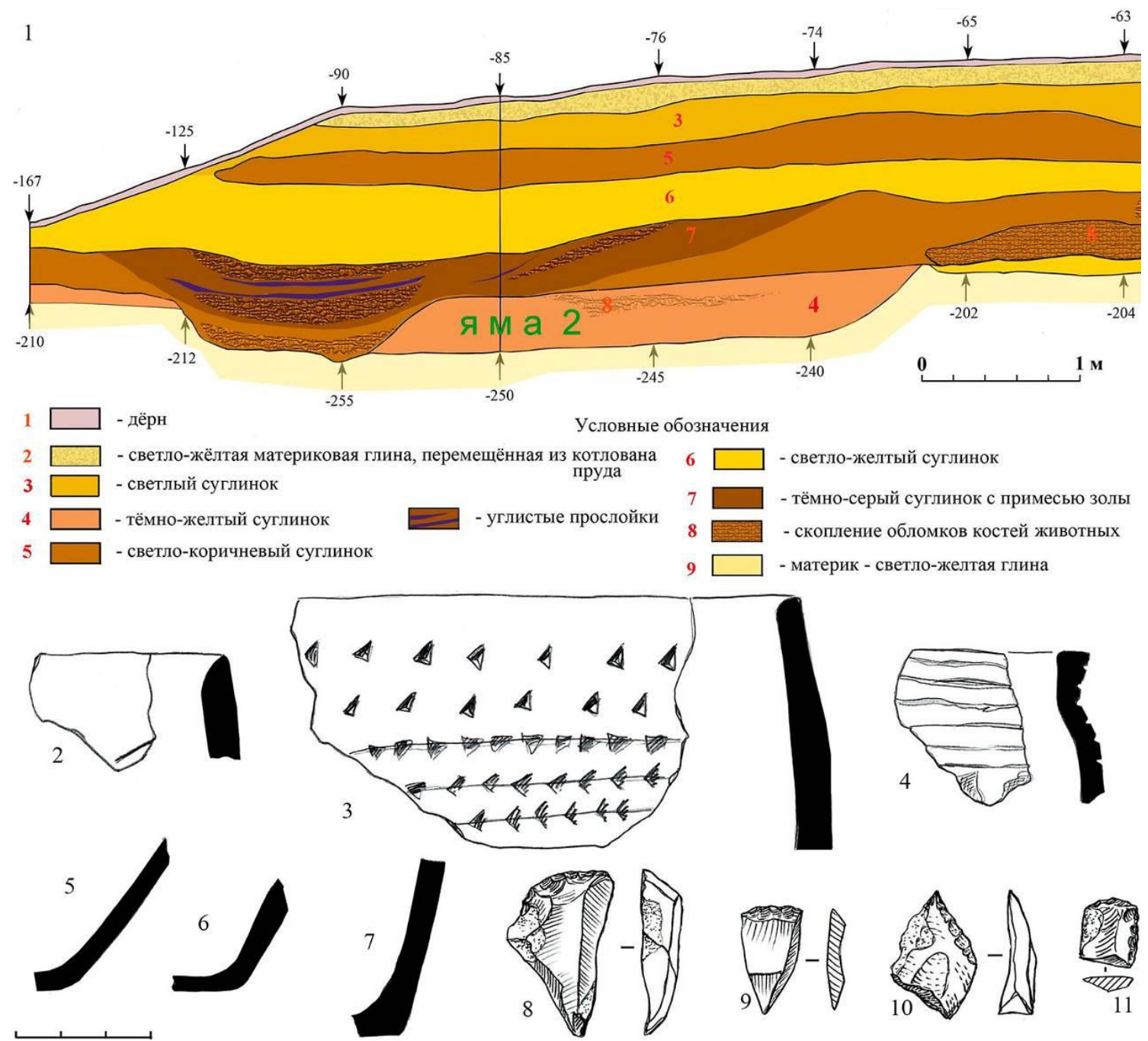

Рисунок 1 - Поселение Орошаемое. Стратиграфия раскопа Алгай 1 (1) и находки из нижнего слоя (2-11)

Во всяком случае, совершенно аналогичная картина наблюдалась и на Варфоломеевской стоянке, когда после первого года раскопок несколько локальных участков осветленного нижнего культурного слоя воспринимались как заполнение ям и котлованов и только на второй год раскопок они слились в единый литологический горизонт.

Керамика из вышеописанной «ямы» представлена фрагментами от нескольких сосудов, орнаментированных отступающим наколом и прочерком. (рис. 1: $2-7)$ и находит полные аналогии в нижнем слое Варфоломеевской стоянки. Немногочисленные каменные орудия из ямы 2 - скребки на пластинах, перфоратор (рис. 1: 8-11) - также вполне сопоставимы с находками из нижнего варфоломеевского слоя.
На раскопе Алгай 2 (в 38 м к северо-востоку от раскопа Алгай 1) также стратиграфически выделяется нижний горизонт неолитического слоя (стратиграфический слой 9). Он сложен светло-серым суглинком, аналогичным заполнению ямы 2 на раскопе Алгай 1. Слой залегает на всем протяжении небольшого $\left(16 \mathrm{M}^{2}\right)$ раскопа Алгай 2, затронувшего часть котлована полуземлянки. Верхняя граница слоя размыта, нижняя граница размыта по бортам котлована и хорошо выражена по дну. Количество неолитических находок уменьшается по мере углубления, и в нижней части слоя они единичны. Данный слой - заполнение котлована, но распространяется и за его пределы (рис. 2: 1). 

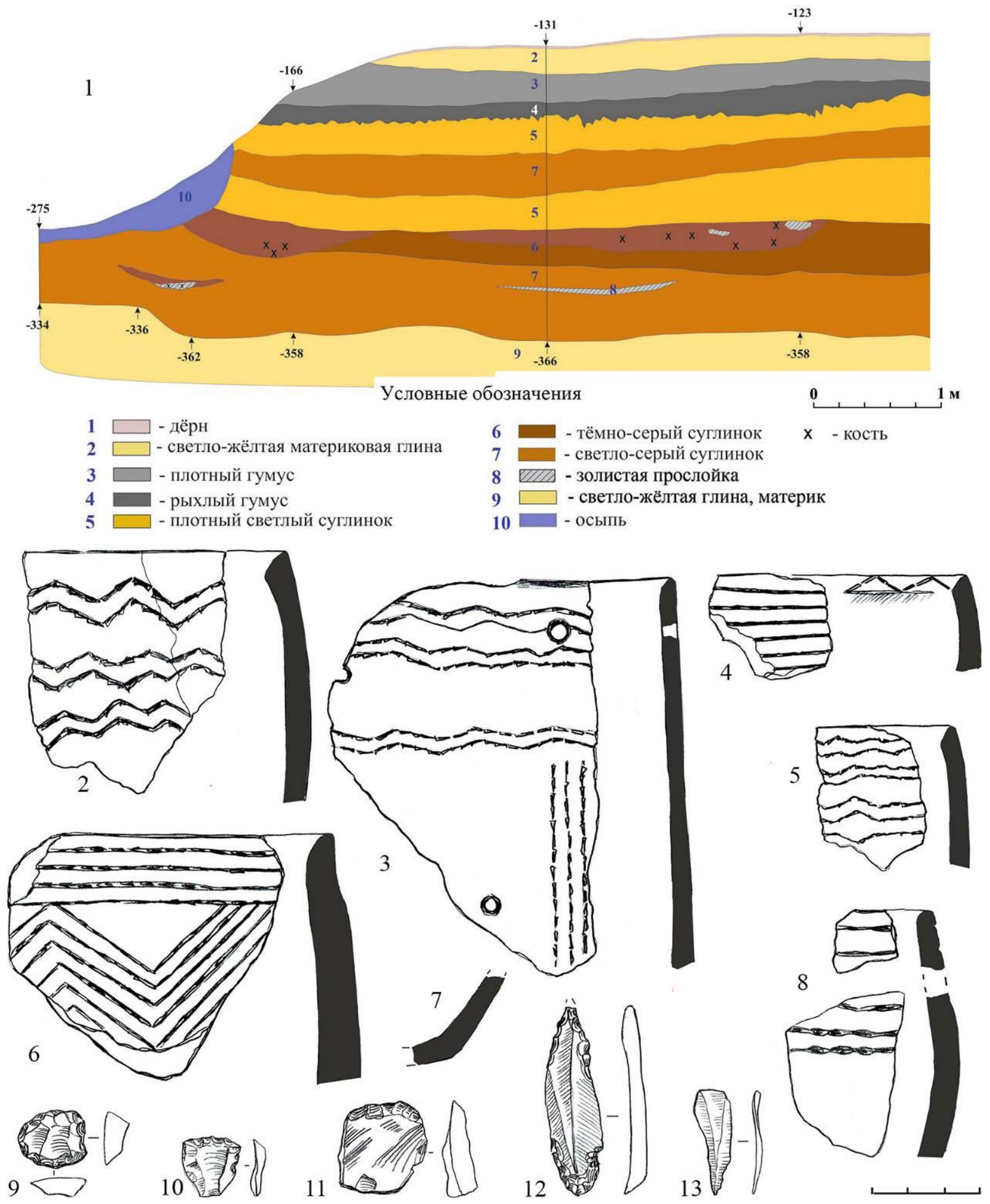

11

12

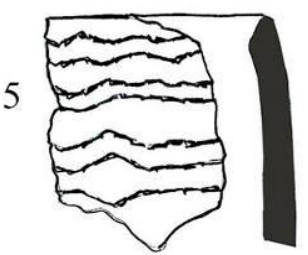

Рисунок 2 - Поселение Орошаемое. Стратиграфия раскопа Алгай 2 (1) и находки из нижнего слоя (2-13)

Керамика этого слоя также имеет все основные признаки, свойственные орловской посуде, и, несмотря на свою малочисленность, вполне сопоставима с варфоломеевской из нижнего слоя. Она имеет обычную примесь толченой раковины в тесте глины, орнаментирована узким подтреугольным отступающим наколом (рис. 2: 2-8). Орнаментальные композиции составлены из горизонтальных и вертикальных рядов прямых линий и зигзага - наиболее часто встречаемых на ранней орловской керамике.

В качестве сырья для каменных предметов - отщепы, чешуйки, сколы, пластины, скребки и проколка - использовался только кремень (рис. 2: 9-13), что тоже является отличительной особенностью нижнего слоя Варфоломеевской стоянки, где абсолютное большинство каменных орудий изготовлено из кремня. Вероятно, находки слоя 9 в раскопе Алгай 2 относятся к наиболее раннему времени существования стоянки и синхронны нижнему слою раскопа Алгай 1, где была получена вышеприведенная дата 6271-6008 cal BC.

Небольшие коллекции из описанных выше участков нижней части неолитического культурного слоя на раскопах Алгай 1 и Алгай 2 сами по себе не дают возможности дать полноценную характеристику раннего неолита степного Поволжья. Это относится и к нижнему слою раскопа Орошаемое, где получены две ранние даты, но находки выразительной керами- 
Юдин А.И., Выборнов А.А.

ки и характерных каменных орудий единичны. В то же время, полученные радиокарбонные даты согласуются со стратиграфическими данными. Основываясь на ранних датах поселения Орошаемое и Варфоломеевской стоянки, для всесторонней характеристики раннего этапа орловской культуры вполне корректно привлечь материалы нижнего слоя последней. Он содержит достаточно представительную выборку плоскодонной керамики с накольчато-прочерченной орнаментацией и микролитичных каменных орудий на пластинах для характеристики раннего этапа орловской культуры. Исходя из развитого облика керамики нижнего слоя Варфоломеевской стоянки и имея всего лишь одну дату с широким доверительным интервалом, нижний слой был отнесен к среднему этапу местного неолита [1, с. 145-146]. Это вступило в настоящее время в противоречие с имеющимися данными о раннем неолите и неолитизации региона.

Большое количество аналогий орловской культуре по целому ряду параметров в материальных комплексах неолитических стоянок Каиршак III в Северном Прикаспии и поселений Раздорское I и Ракушечный Яр на Нижнем Дону отмечалось ранее [12, c. 41-57]. Радиоуглеродная хронология подтвердила их синхронность.

Сделанные выводы на основе новых полевых исследований и радиокарбонных дат подтверждаются и работами по изучению технико-технологического анализа керамики. На основе многолетних исследований керамики И.Н. Васильева приходит к выводу, что керамические традиции населения Нижнего Поволжья относятся к ареалу древнейшего гончарства в Восточной Европе [13, с. 11-13].

Достаточно ранние даты поселения Орошаемоге и нижнего слоя Варфоломеевской стоянки, а также ряд параллелей с Ближним Востоком в керамике, орудиях из камня и предметах искусства дают основание предполагать активное участие населения орловской культуры в процессе неолитизации ЮгоВосточной Европы и широкие контакты с населением не только сопредельных регионов, но и достаточно удаленных от Нижнего Поволжья [14, с. 191-200; 15 , с. 42-77].

Установление наличия ранних слоев неолита на двух основных памятниках орловской культуры Варфоломеевской стоянке и поселении Орошаемое (раскопы Орошаемое, Алгай 1 и Алгай 2) вызывают необходимость пересмотреть предложенную ранее одним из авторов периодизацию орловской культуры $[1 ; 16$, с. 3-22], согласно которой памятники раннего этапа были неизвестны, средний этап неолита представлен материалами нижнего (3) слоя Варфоломеевской стоянки, поздний этап - слоями 2Б и 2 А.

Требуется небольшая, но весьма существенная корректировка. Попытки найти ранние памятники не увенчались успехом по простой причине. Материалы раннего этапа орловской культуры были интерпретированы на уровне данных 1995 года при слабой источниковой и сравнительной базе, единичных датах: ранние материалы нижнего слоя Варфоломеевской стоянки были отнесены к среднему неолиту. Раскопки поселения Орошаемое, серия новых радиоуглеродных дат и технико-технологическое изучение керамики [13, с. 6-16; 17, с. 104-123] показали, что нижний слой Варфоломеевской стоянки включает находки раннего неолита. У нас нет оснований не доверять полученным датам по органике в керамике, так как их значительная часть совпадает со значениями по другим органическим материалам. Это подтверждает вывод специалистов по радиоуглеродному анализу о приемлемости датировок по керамике [18]. В этой связи уместно напомнить, что по керамике из предматерикового уровня Варфоломеевской стоянки получены даты более древние, чем 7200 лет ВР. Весьма важно, что, по данным И.Н. Васильевой, керамика из нижнего уровня 3 слоя этого памятника изготовлена из ила с естественной примесью раковин пресноводных моллюсков, что является древнейшей технологией изготовления посуды эпохи неолита.

Совершенно очевидно, что периодизация орловской культуры теперь выглядит так: ранний неолит нижний слой Варфоломеевской стоянки и нижние слои раскопов на поселении Орошаемое; средний неолит - слой 2Б Варфоломеевской стоянки; поздний неолит - слой 2А Варфоломеевской стоянки.

Тем не менее ранние орловские материалы, особенно в части керамического комплекса, показывают удивительное многообразие в формах сосудов и их орнаментации. Это заставляет предполагать возможность наличия какого-то стороннего культурного импульса на начальном этапе неолитизации, который мы пока не в состоянии проследить археологически.

\section{Список литературы:}

1. Юдин А.И. Варфоломеевская стоянка и неолит степного Поволжья. Саратов: СГУ, 2004. 200 с.

2. Васильев И.Б., Выборнов А.А. Неолит Поволжья (степь и лесостепь). Куйбышев: КГПИ, 1988. $112 \mathrm{c}$.

3. Кольцов П.М. Поселение Джангар в Сарпинской низменности // Эпоха меди юга Восточной Европы. Куйбышев: КГПИ, 1984. С. 79-91.

4. Кольцов П.М. Неолитическое поселение Джангар // Археологические культуры Северного Прикаспия. Куйбышев: КГПИ, 1988. С. 52-92.

5. Выборнов А.А., Козин Е.В., Неолитическая стоянка Каиршак 1 в Северном Прикаспии // Археологические культуры Северного Прикаспия. Куйбышев: КГПИ, 1988. С. 92-105.

6. Васильев И.Б., Выборнов А.А., Козин Е.В. Исследование неолитической стоянки Каир-Шак III // Неолит и энеолит Северного Прикаспия. Куйбышев: КГПИ, 1989. С. 18-45.

7. Барацков А.В., Выборнов А.А., Кулькова М.А. Проблемы абсолютной хронологии неолита Северного Прикаспия // Известия Самарского научного центра Российской академии наук. 2012. Т. 14, № 3. C. 200-204.

8. Радиоуглеродная хронология неолита Восточной Европы в VII-III тыс. до н.э.: кол. моногр. / сост. Г.И. Зайцева, О.В. Лозовская, А.А. Выборнов, А.Н. Мазуркевич. Смоленск: Свиток, 2016. 456 с.

9. Выборнов А.А., Юдин А.И., Васильева И.Н., Кулькова М.А., Косинцев П.А., Гослар Т., Дога Н. Новые данные по неолиту - энеолиту Нижнего Поволжья // Известия Самарского научного центра Российской академии наук. 2015. Т. 17, № 3. С. 235-241.

10. Выборнов А.А., Юдин А.И. Исследования в Александрово-Гайском районе Саратовской области 
в 2015 году // Археологическое наследие Саратовского края. Вып. 14. Саратов, 2016. С. 3-41.

11. Выборнов А.А., Юдин А.И. Исследования в Александрово-Гайском районе Саратовской области в 2016 году // Археологическое наследие Саратовского края. Вып. 15. Саратов, 2017. С. 30-78.

12. Юдин А.И. Культурные контакты и связи населения Нижнего Поволжья в неолитическое время // Нижневолжский археологический вестник. Вып. 3. Волгоград, 2000. С. 41-57.

13. Выборнов А.А., Васильева И.Н., Кулькова М.А., Филиппсен Б. О времени появления и динамике распространения керамических традиций в степном Нижнем Поволжье // Вестник Волгоградского государственного университета. Серия 4. История. Регионоведение. Международные отношения. 2018. Т. 23, № 2. С. 6-16.

14. Юдин А.И. Орнаменты костяных изделий Варфоломеевской стоянки как отражение культурных взаимодействий // Культуры степной Евразии и их взаимодействие с древними цивилизациями: материалы междунар. науч. конф., посв. 110-летию со дня рождения выдающегося российского археолога
Михаила Петровича Грязнова. Кн. 1. СПб., 2012. C. 191-200.

15. Юдин А.И. О культурных взаимодействиях неолитического населения Степного Поволжья и Среднего Зауралья // Археологическое наследие Саратовского края. Вып. 14. Саратов, 2016. С. 42-77.

16. Юдин А.И. Культурное развитие населения Нижнего Поволжья в неолите и энеолите // Археологическое наследие Саратовского края. Вып. 7. Саратов, 2006. С. 3-22.

17. Васильева И.Н., Выборнов А.А. Время появления и динамика распространения неолитических керамических традиций в Поволжье // Поволжская археология. 2016. № 3 (17). С. 104-123.

18. Зайцева Г.И., Скаковский Е.Д., Посснерт Г., Выборнов А.А., Ковалюх Н.Н., Скрипкин В.В. Органическое вещество керамики: природа, органические компоненты и достоверность радиоуглеродных дат // Труды III всерос. археологического съезда. T.II. СПб. - М. - В. Новгород, 2011. С. 383-385.

Работа выполнена в рамках проекта № 33.1907/ ПЧ государственного задания Министерства образования и науки РФ.

\title{
NEW DATA ABOUT THE EARLY NEOLITHIC OF THE STEPPE VOLGA REGION
}

(C) 2018

\author{
Yudin Aleksandr Ivanovich, doctor of historical sciences, deputy director for scientific work \\ Research Center for the Preservation of Cultural Heritage (Saratov, Russian Federation) \\ Vybornov Aleksandr Alekseevich, doctor of historical sciences, professor, \\ head of Domestic History and Archeology Department \\ Samara State University of Social Sciences and Education (Samara, Russian Federation)
}

Abstract. The issue of early Neolithic isolation in various territories is one of the most difficult to study. The early Neolithic steppe Volga Region was unknown for a long time. This is due to the small number of Neolithic monuments in the region of interest. The situation changed after the study of the Varfolomeevskaya site. The lower layer of this reference monument of the Orel culture belonged to the Middle Neolithic, layers 2B and 2A - to the late Neolithic. This version was based on a limited source base and a few radiocarbon dates, some of which were of a debatable nature. New field surveys in 2014-2017 on three excavations in Oroshaemoe Settlement and significant series of radiocarbon dates for various organic materials obtained in various laboratories (including AMS) allowed us to revise the periodization of both the Varfolomeevskaya site and the Oryol culture on the whole. This allows you to make a typological analysis of materials, as well as technical and technological analysis of ceramic implements. Thus, the earliest ceramics are made from silt with a natural admixture of shells of mollusks. The lower layer of the monument is now defined as Early Neolithic, layer 2B - the Middle Neolithic, layer 2A - late Neolithic.

Keywords: steppe Volga Region; Northern Caspian; site; early Neolithic; Middle Neolithic; late Neolithic; Orel culture; ceramics; stone implements; stratigraphy; periodization; chronology; radiocarbon dating; technical and technological analysis.

УДК 902.01

Статья поступила в редакцию 10.06.2018

\section{СРАВНЕНИЕ ГЕОМЕТРИЧЕСКИХ МИКРОЛИТОВ ПАМЯТНИКОВ НИЖНЕГО ПОВОЛЖЬЯ И НИЖНЕГО ПОДОНЬЯ}

(C) 2018

Смагин Валерий Андреевич, магистрант кафедры отечественной истории и археологии Самарский государственный социально-педагогический университет (2. Самара, Российская Федераџия)

Аннотация. Геометрические микролиты присущи практически всем памятникам мезолита и неолита на территории Нижнего Поволжья. Для стоянок интересуемой территории они играют ключевую роль. С помощью данного вида орудий труда можно определить культурную принадлежность и хронологическую позицию изученных памятников. В данной публикации рассматриваются преимущественно неолитические стоянки на территории Нижнего Поволжья и Нижнего Подонья, которые имеют в каменном инвентаре геометрические микролиты. В большинстве своем эти памятники обладают достаточно устойчивыми сериями орудий геометрического типа, что позволяет сравнивать их между собой и проводить параллели. Приведены результаты радиоуглеродного датирования для неолитических памятников Нижнего Поволжья и Нижнего Подонья. Имеется трасологическое и типологическое сравнение данных стоянок. В статье обсуждаются 